\title{
Evaluation of Moisture Transfer to Improve the Conservation of Tiles Finishing Facades
}

\author{
Silvia Erba, Bruno Daniotti, Elisabetta Rosina, Antonio Sansonetti \\ and Riccardo Paolini
}

\begin{abstract}
The research of methodologies and tools to improve the durability of building components has the aim to find out the strategies to increase the service life, minimizing the environmental impacts. The paper refers on clinker facades, especially after the repairs of mortars due to severe damages. The authors achieved on-site investigations on a prominent study case in Leonardo Campus, at Politecnico di Milano, and laboratory tests to study the interaction between moisture and cement mortars, the decay effects, and the protective treatments to improve the mortar durability. The research sharpens the methods for the evaluation of water absorption and moisture transfer in external building components and proposes possible strategies of intervention. The methodology focuses on the characterization of the water behavior in mortars by different tests, the experiments in laboratory on mortars samples, to study the hygroscopic and capillarity absorption properties, and on site, through visual analysis and nondestructive techniques. The researchers studied a water-repellent protective treatment to apply on the finishing surface and evaluated it in terms of water-repellent efficacy, compatibility with the substrate, vapor permeability, and color stability. The investigations provide input data, useful for simulating the moisture transfer, validating the experimentations, and modeling the physical mechanisms, which occur on the façade. In addition, the method
\end{abstract}

\footnotetext{
S. Erba $(\bowtie)$ - B. Daniotti - E. Rosina · R. Paolini

Politecnico Di Milano, Milan, Italy

e-mail: silvia.erba@polimi.it

B. Daniotti

e-mail: bruno.daniotti@polimi.it

E. Rosina

e-mail: elisabetta.rosina@polimi.it

R. Paolini

e-mail: riccardo.paolini@polimi.it
}

\section{A. Sansonetti}

Consiglio Nazionale delle Ricerche, Istituto per la Conservazione e Valorizzazione dei Beni Culturali (National Research Council, Department for the Conservation and Valorization of Cultural Heritage), Milan, Italy

e-mail: a.sansonetti@icvbc.cnr.it 
analyses also the optical characteristics of the surface, with the aim to detect any change due to the application of further protective treatments and for aging process.

Keywords Moisture $\cdot$ Cements $\cdot$ Mortars $\cdot$ Water-repellent treatment $\cdot$ Durability

\section{Introduction}

The research of methodologies and tools to improve the durability of building components aims to find strategies to increase the service life, minimizing the environmental impacts (Nicolella 2003).

For existing buildings, the residual service life is the time span remaining after considering a specific moment. To assess the residual service life of an inspected building or component is crucial to reconstruct its conservation history, i.e., data on the original performance values, information on the installation, maintenance, trends of deterioration, etc.; several difficulties and the lack of information regarding the initial state prevent the complete achievement of this task. The process of assessment of the residual service life allows also to plan the remaining part of the service life, the performance levels to maintain equal or higher than the accepted threshold of the decreased service (Daniotti 2009).

As regards the listed contemporary buildings, a mandatory issue drives to the preservation of the original materials and features, together with keeping the residual service life of their components and system; therefore, the preservation criterion overcomes the functional criterion of maintaining the performance level by replacing the components before the end of their service life.

Therefore, the evaluation of risk factors and damage processes is the most important step for preventing decay, planning the effective routines for the early detection of anomalies, and constantly protecting the weakest part of the system.

The paper refers to a research aimed at improving the durability of clinker facades, especially after the repairs of mortars after severe damages. The authors achieved on-site investigations on an important study case in Milan and laboratory tests to study the interaction between the moisture and cement mortars, the decay effects, and the treatments to improve the mortar durability.

\section{Planning Conservation Works in Humid Environment}

The facades cladding is composed of cement mortar layers on which clinker tiles are applied. Therefore, the complete system of finishing includes the superimposition of mortar layers with different compositions and surface morphology. Moreover, the line between the tiles edges and the mortar constitutes a possible gap in the outer layer and therefore a vulnerable line for the infiltration of water, and it increases the risk of triggering damages. 
The application of water-repellent treatments on the mortar is a new frontier for the conservation plans of cultural heritage. The protective treatment has the requirement to guarantee a hydrophobic performance, reducing the presence of water on the surface and near-surface regions. At the same time, a proper protective layer guarantees the water vapor permeability (Amoroso and Fassina 1983). These treatments slow the transformations of the materials due to the decay processes, caused by aggressive external agents, and the imbalances in the boundary conditions.

The researchers tested two different mortar mix designs based on cement, performing several tests to evaluate the water transport phenomena and the radiation properties. At a second step, they applied a water-repellent polymeric treatment on the mortar surface; after an appropriate curing time, they repeated the same tests.

In other words, the authors evaluated the water-repellent effectiveness through a series of laboratory tests and computer-based simulations, including the evaluation of the compatibility with the substrate, the color variations, and the permanence of the vapor permeability. A further step of the research will include the assessment of the durability of the system substrate/polymer through accelerated aging cycles varying temperature, relative humidity, and solar irradiance and also the investigations on the real site.

\section{Case Study}

\subsection{Città Studi, Sustainable Campus; Monitoring the Klinker Facades}

The case study here presented is a building inside the "Leonardo Campus," Politecnico di Milano, see also Fig. 1, on which the researchers assessed the state of conservation within the research "Città Studi, Sustainable Campus." The Campus is representative of many typologies of contemporary buildings. The study case has an exterior cladding system of tiles. The facades materials, exposed to excessive rainwater infiltration or critical moisture content, show a visible damage and have a consequent reduction of their durability. Scientific literature reports the prediction about exterior finishing and cladding systems service life and the use of degradation models (Sousa 2008; Emídio 2012). In each case study, the phase of diagnostic knowledge represents an essential step aimed at the definition of the correct strategies of intervention to prevent the occurrence of failure and maintain, manage, and valorize the building components.

The researchers developed and validated the investigative procedure on some buildings with tiles cladding systems (buildings $n 12,14,15$, see Fig. 1), and later, they applied the procedure on buildings with plaster finishing (buildings $n 1,2,3$ ).

\footnotetext{
${ }^{1}$ http://www.campus-sostenibile.polimi.it/home.
} 
Fig. 1 Map of Leonardo Campus

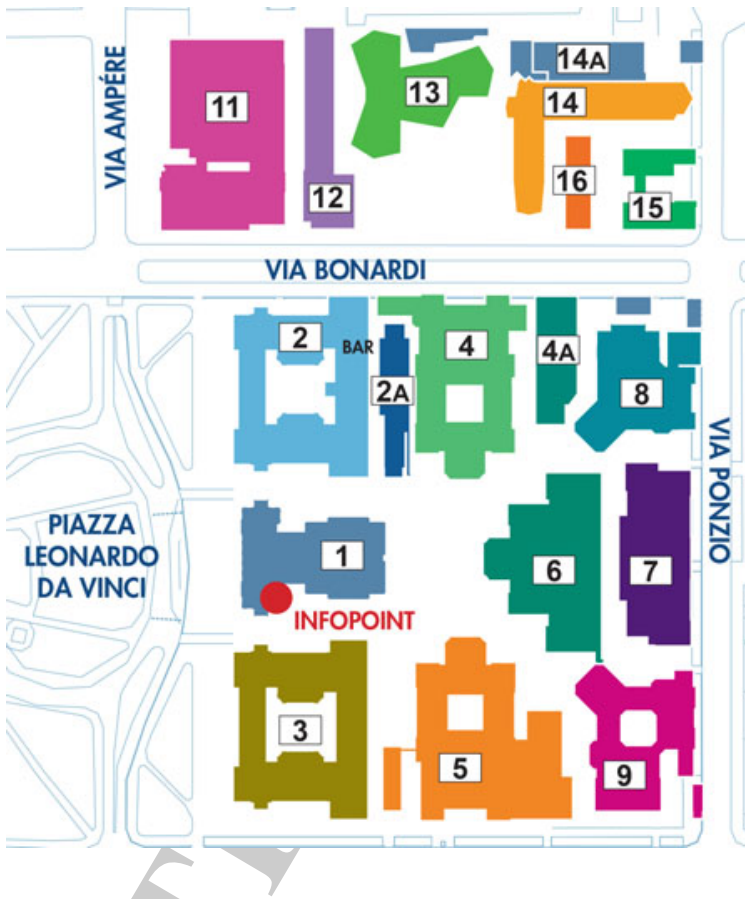

Stoneware tiles cladding is a diffused rendering practice in Italy since the 19501960s, due to the good wear resistance, high temperatures stability, hardness, tenacity, and thermal inertia. Moreover, the durability of the ceramic materials, their low cost, and low sensitivity to the effects of pollution are some of the reasons of their application in the middle-southern region of Europe (Velosa et al. 2011). After 50 years of usage, the façades present a severe decay pattern, such as delaminations, missing tiles, and discoloration; this is due to the action of atmospheric agents, loss of adherence at the interfaces tile/mortar/support, and the absence of a correct maintenance. Giò Ponti, one of the most famous architects of 1950-1980s, designed some buildings in the Campus, and at present, their facades urgently require maintenance. The assessment of these façades is an important issue both for the economic aspects related to the costs of maintenance and for the repair project that deals with contemporary buildings having high historical-artistic value. From this side, preserving the authenticity of the building is a critical issue. At the current state of the debate, restorers generally accept that the repair should be clearly identifiable from a short distance. On the contrary, a "mimetic" solution, with the substitution of materials and elements with new ones "a l'identique," is a practice that does not fit the conservation requirements. Therefore, the need to limit as much as possible the substitution rises up, preventing the damage by reducing the risk factors (environment, building techniques, use, lack of maintenance, etc.) by monitoring the degradation phenomena evolutions, and by means of a conservation plan.

Delamination, as defined by ICOMOS glossary (International Scientific Committee 2008), is the detachment process affecting laminated stones. It 
Fig. 2 Distribution of the characteristic thermal gradient due to detachment in tiles cladding systems as a function of the orientation to the mechanical stress. (Maldague 2001). Freitas et al. 2014) (Fig. 2).

corresponds to a physical separation into one or several layers following the natural cleavage present in the stone. This definition, applied to artificial stone materials as mortars or cladding systems, regards the adhesion defects, and after that, decay mechanism creates an air gap at any interface.

The most frequent cause regards infiltrations inside the structure, the water evaporation, and the crystallization of soluble salts inside the pore matrix. The growth of salts inside the finishing causes the detachment of the exterior layers due

Therefore, it is important to localize and map the presence of these defects for the activation of maintenance. The assessment costs mainly depend on renting elevators/forklift truck or scaffolding; therefore, the use of remote testing, that does not require to touch the surface, implicates a strong reduction of costs.

Infrared thermography (IRT) techniques fully proved to be suitable at this aim

IRT monitoring allows to check the results also after the repair, through monitoring and assessment of new delaminations.

This technique has already shown its critical points. The presence of chromatic alterations on the façade, obstructions and shades, different reflectance, and local lacks of homogeneities can mislead the pathologies identification.

The use of IRT can be at transient or steady-state conditions: in the case of adhesion problems, it is fundamental to create a temperature transitory to visualize the map of the state of adhesion on the façade (Caglio et al. 2011; Ludwig et al. 2012). With this procedure, it is possible to evaluate a thermal gradient between sound and detached areas. Natural or artificial sources of heating successfully generate the proper thermal gradient for detecting the delamination. The researchers validated the results also by numerical simulation through WUFI ${ }^{\circledR}$ software (De

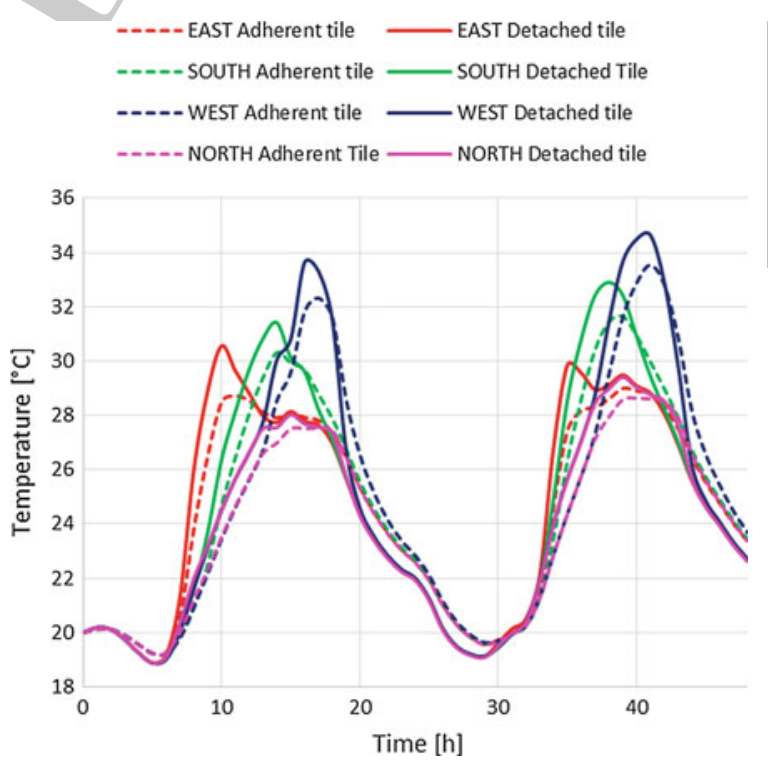




\subsection{Description of Building 12 and Diagnostics of the State of Conservation}

Building 12 has an exterior stoneware tiles cladding (Fig. 3, left). The ceramic elements, flamed at high temperature (producer Italian Society of Grès, now Italcementi s.p.a.), are no longer under production. The body of the material is compact, and the superficial layer presents the typical glaze obtained through a vitrification while firing; the glaze thickness is around $50 \mu \mathrm{m}$, except for the corner tiles where it is enhanced at $150 \mu \mathrm{m}$ (Fig. 3, right). The underneath layer is a cement mortar bedding $4 \mathrm{~cm}$ thick.

IRT was used after $2 \mathrm{~h}$ of solar heating on Building 12. The thermal anomalies due to clinker tile delaminations were the target of the investigation.

This time span permitted to obtain the better contrast between delaminated areas and sound ones.

Cladding thickness and thermal characteristics, the presence and depth of defects, and environmental conditions (air $\mathrm{T}$ and $\mathrm{RH}$, wind speed, solar irradiance) play a prominent role in the heat diffusion through the cladding itself.

As a result of the surveys phase, a series of pathological failures have been listed and classified according to the associated damage. The most spread and severe damage resulted the detachment, since it represents a source of danger in particular in the case of public buildings, such as a university; hence, the delamination requires a timely intervention for safety reasons (Re Cecconi 1996).
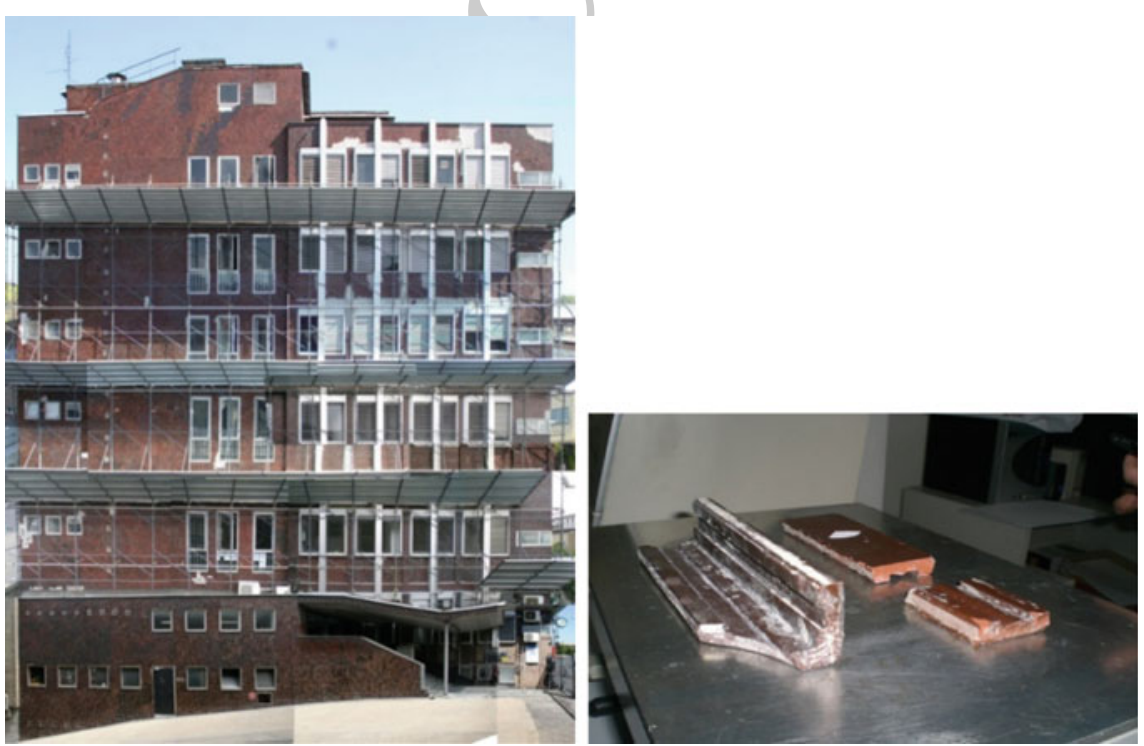

Fig. 3 Building 12 in Campus Leonardo (left); details of the tiles of Building 12 (right) 
Incorrect design and application are supposed to cause the majority of detachments and missing tiles. The areas where design errors caused the damages are mainly located close to the windows: the loss of adherence could be due to water infiltrations through the sill and the mullions, in the junction between the wall and the window frames. Rainwater can remain stagnant at the top of the window frames, because of the profile insufficiently leaning, causing the corrosion of the steel frames. Execution errors mainly deal with the mortar and to its high thickness (around 3-4 cm) where the several layers are not always adherent to each other's.

Cracking are also supposed to be mainly related to unsuitable design and application, because of the excessive shear stresses between tiles and support (due to the lack of the expansion joints) and the wrong choice and laying of the adhesive and substrate.

In addition to the IRT scanning and thermal analysis, the researchers completed the diagnostics by analyzing some samples of the facades materials and their decay products. Microscopic observations confirmed that the body of the tile is a compact ceramic material, very similar to earthenware, and the tiles have a finishing glazed layer; corner tiles do not differ from the others. EDS analyses of mortar samples resulted a common cement binder and sand as aggregate.

\section{Moisture and Protective Treatments}

\subsection{Moisture Transport Mechanisms and Damages}

The penetration of water in the structures causes a general decrease of their mechanical performances, depending on the absorption ability of the materials and their level of soaking (Coppola 1996). The causes of damage range from mobility of soluble salts, their crystallization inside the pores structure, freeze and thaw cycles, hydric expansion, and biological growth. Damage is located mainly on the surfaces (exfoliation, pulverization, efflorescence); otherwise, it can reach the bulk, causing cracks even across the section of the walls depending on the time of weathering exposure, the typology of building material, and the thickness of masonry. National and international standards provide the appropriate procedures to measure the specific parameters, which are helpful to evaluate the physical decay mechanisms and kinetics. In fact, the source of water infiltrations, their path into the structure, and their transport cycles in a short time determine the potential increasing of the existing damage.

Because of the previous surveys and analysis, the researchers chose two cement mortars (CEM I and IV) for bedding and prepared 36 specimens (18 of each type; dimensions $5 \times 5 \times 2 \mathrm{~cm}$ ) for the laboratory investigations. 


\subsection{Consolidation and Protective Treatments}

The use of consolidation and water-repellent treatment on natural stones is well known (Toniolo et al. 2002; Tsakalof et al. 2007). Many different organic compounds have been used as coatings for building materials (Horie1987; Amoroso and Camaiti 1997) such as natural and synthetic waxes, acrylic resins, siloxanes perfluoropolyethers, fluorinated polyolefin, and fluoroelastomers. These different polymeric materials have been often used without an adequate knowledge of the properties of the polymer/stone system; therefore, the application did not reach an optimal formation of the final system. As a result, the treatment resulted not satisfactory for the insufficient protection effectiveness and/or the permanence on the substrate.

The term protective treatments identifies a range of products, materials, and structures, which play a defense action on building components against natural weathering or human actions. Systems, materials, and procedures can achieve the protective function, based on both active and passive interventions. The passive protection prevents the beginning of a process of degradation, acting on the causes of the degradation and/or around the component. This category includes screens, roofs or barriers (provisional or definitive), canopies, flashings, and overhangs. The active protection consists in the application of products on the surface to improve (reach) the water repellency of the protected matter. Hence, the protective treatments seek to slow the probability of transformations of the materials, because of aggressive external agents transported by water and imbalance with the surrounding environment.

In some cases, the protective products display properties similar to those of the ones under protection; nevertheless, their first requirements is to ensure water repellency and water vapor permeability.

The water repellency reduces the absorption of water into the material porosity. A good permeability allows the water vapor to pass through the material, avoiding any "barrier effect" which should accumulate water in a localized area.

\subsubsection{Siloxane Treatments}

Among the different protective products available on the market at present, the experimentation focuses on siloxanes, which are used since 1960 on natural stone; despite the application since a long time, less investigation focused on their application on artificial materials (Maravelaki-Kalaitzaki 2007; Allen et al. 1992). Siloxanes are organosilicon compounds; they form usually the backbone of the so-called silicones, and they are able to impart water repellency when applied to any surface. They show their chemical stability due to the $\mathrm{Si}-\mathrm{O}$ bond. Once cured, they abate the penetration of water inside the pore structure, allowing a good water vapor permeability. Moreover, they are stable at atmospheric agents and do not change the substrate color, and they are not toxic. Nevertheless, there are also negative aspects, 

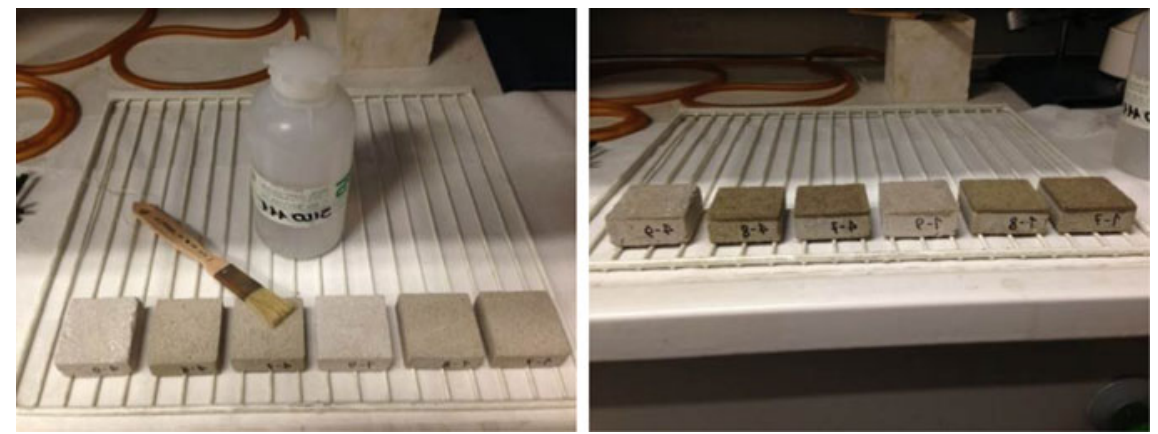

Fig. 4 Application of the water-repellent siloxane treatment on the outer surface of cement mortar samples (CEM I and IV)

among which the scarce durability in the presence of sulfur dioxide (Mavrov 1983). The researchers chose the product CTS SILO 111, which substituted the less recent CTS 111, due to its common use in the restoration field (Fig. 4). Moreover, a vast bibliography exists, and it supports the study of its performances in several different conditions, comparing their performances with the ones of other products.

Different parameters affect the choice of a protective treatment:

- water-repellent effectiveness,

- chemical inertia with respect to the substrate,

- long-lasting vapor permeability,

- resistance to thermo-hygrometric variations,

- heat resistance,

- UV aging resistance, and

- penetration ability.

Erba (2015) refers about many investigation on the water-repellent effectiveness through a series of laboratory tests and computer-based simulations, the compatibility with the substrate and the chromatic alterations, and the permanence of the vapor permeability after the application of the product, all evaluated at the so-called time $t_{0}$ (after the curing of the polymeric treatment). In the following, the authors present and discuss the results of the laboratory tests and simulations.

\subsection{Treated Mortars Properties for the Protection of Humid Walls}

According to the German standard DIN4108-3 (Künzel et al. 2004), adequate plaster and protective layers for the protection of humid walls must present the following properties: 
- water vapor diffusion-equivalent air layer thickness $\left(S_{\mathrm{d}}\right)$ lower than $2 \mathrm{~m}$,

- water absorption by capillarity $(A)$ lower than $0.5 \mathrm{~kg} / \mathrm{m}^{2} \mathrm{~h}^{0.5}$, and

- product of $\mathrm{Sd}$ and $A$ lower than 0.2 .

To fulfill these requirements, the authors tested different mixture for mortars by performing absorption tests such as the absorption by capillarity and the water vapor transmission tests. After this first step, they placed on the mortars' surface a water-repellent polymeric liquid treatment, and the tests were repeated.

\section{Experimental Setup, Tests for the Characterization of Water Transport Phenomena, and Radiation Properties of Treated/Untreated Samples}

The first step of the experimental research concerned the characterization of the water transport phenomena. The specimens for each type of mortars, having dimensions $5 \times 5 \times 2 \mathrm{~cm}$, were tested before and after the application of the protective treatment. The second part reports the results of the color and solar spectral reflectance test.

List of the laboratory tests:

- hygroscopic absorption (UNI EN 12571),

- water absorption by capillarity (UNI EN 15801),

- water absorption by partial immersion (UNI EN ISO 15148),

- long-term water absorption by immersion (UNI EN 12087),

- water vapor transmission (UNI EN ISO 12572), and

- color measures (UNI EN 15886).

In the following, the paper shows the adopted procedures and the results for the tests, underlying the differences between untreated and treated samples. In fact, after the first phase without the treatment, the researchers repeated the tests on the samples with SILO 111 CTS in white spirit $10 \%$, (applied by brush until reaching the condition of surface saturation). They left the specimen at laboratory conditions (T $22 \pm 3{ }^{\circ} \mathrm{C}$; RH $50 \pm 10 \%$ ) for 30 days to guarantee the complete curing of the polymeric product, according to the UNI 10921.

\subsection{Hygroscopic Absorption}

The absorption test was executed in a climatic chamber, according to UNI EN ISO 12571 (2001) (Daniotti et al. 2014a, b) (Fig. 5). The researchers could not obtain the sorption curve values at relative humidity $>90 \%$ due to the technical features of the climatic chamber. The missing values will be obtained in the following part of 

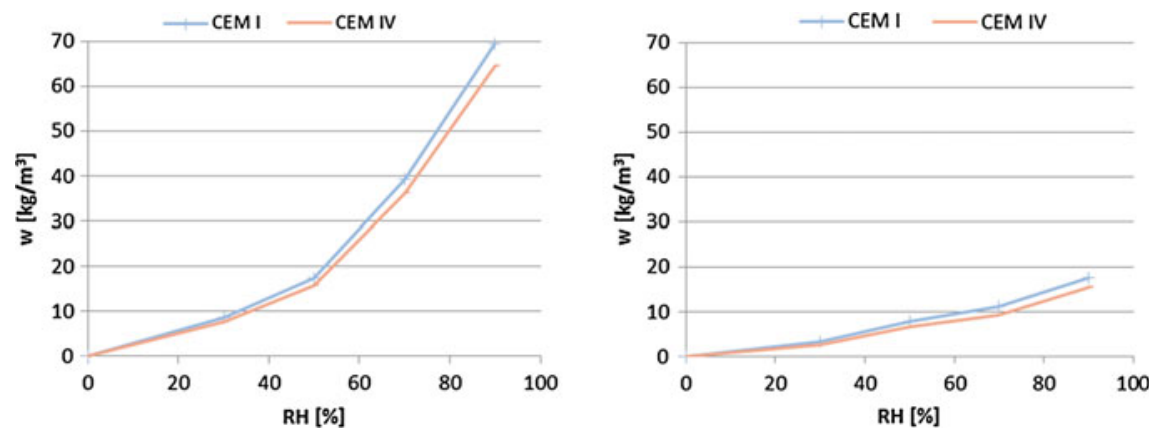

Fig. 5 Relative humidity-moisture content mass by volume (untreated specimens: left; treated specimens: right)

the research, through long-term water absorption by immersion (UNI EN 12087 thermal insulating products for building applications).

Observing the curves is possible to remark the reduction of the moisture content, due to the presence of the product: the tests performed on the specimens resulted with a high difference, and the moisture content decreases from around 70 to $20 \mathrm{~kg} / \mathrm{m}^{3}$.

\subsection{Water Absorption by Capillarity}

The researchers determined water absorption by capillarity applying the standard UNI EN 15801 (2010) (Fig. 6).
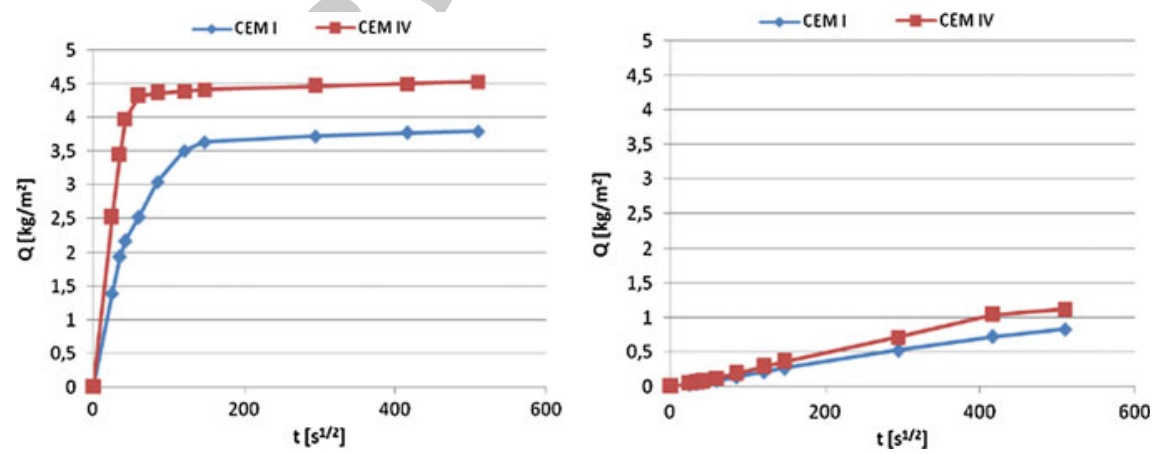

Fig. 6 Curves of capillary water absorption for cement mortars (untreated specimens: left; treated specimens: right) 
Table 1 Capillary water absorption coefficient for the mortars specimens (untreated-treated)

\begin{tabular}{l|l|l|l}
\hline $\begin{array}{l}\text { Type of } \\
\text { mortar }\end{array}$ & $\begin{array}{l}\mathrm{AC}\left(\mathrm{kg} / \mathrm{m}^{2} \mathrm{~s}^{0.5}\right) \text { before } \\
\text { treatment }\end{array}$ & $\begin{array}{l}\mathrm{AC}\left(\mathrm{kg} / \mathrm{m}^{2} \mathrm{~s}^{0.5}\right) \text { after } \\
\text { treatment }\end{array}$ & $\begin{array}{l}\Delta \mathrm{AC}\left(\mathrm{kg} / \mathrm{m}^{2} \mathrm{~s}^{0.5}\right) \text { before- } \\
\text { after treatment }\end{array}$ \\
\hline CEM I & 0.065 & 0.002 & 0.063 \\
\hline CEM IV & 0.100 & 0.003 & 0.097 \\
\hline
\end{tabular}

The diagrams show that the siloxane treatment causes an abatement of the absorbed water. Table 1 shows the value of the absorption coefficient for the different mortars.

It is possible to notice that for both the mortars, the coefficient decreases from untreated to treated mortars. The test result on CEM IV shows the highest reduction in terms of $\mathrm{AC}$ value.

\subsection{Water Absorption by Partial Immersion}

The researchers compared the water absorption values obtained by capillarity and by partial immersion, determining the water absorption coefficient by partial immersion, according to the UNI EN ISO 15148, 2003. The samples were sealed with a sealant to prevent bypassing of the coating.

The main interest of this test was to find out the differences between the AC value and $A_{\mathrm{w}}$ value, since the thermo-hygrometric simulations in WUFI require the results from partial immersion tests.

Figures 7 and 8 show a faster absorption of water (see the darker color of the surface) in the specimens of CEM I with respect to the ones of CEM IV. After $40 \mathrm{~min}$, the water reaches the outer surface.

The water absorption by partial immersion showed results very similar to those performed through capillary tests. The curves have the same trend, and the
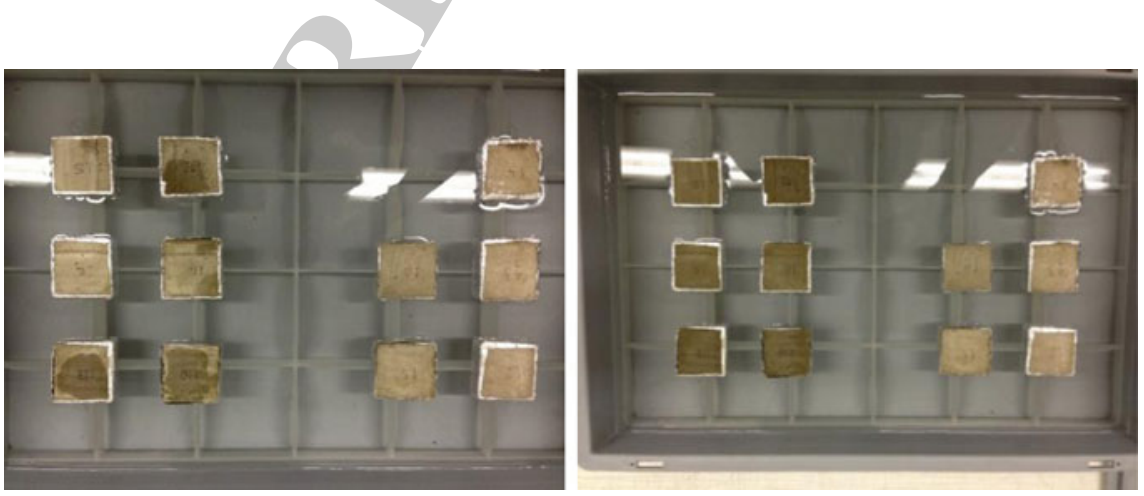

Fig. 7 In each photo, the samples on the left of the basin are untreated, and those on the right are treated. In the photo on the left CEM I specimens after $5 \mathrm{~min}$ and in the photo on the right after $40 \mathrm{~min}$ 

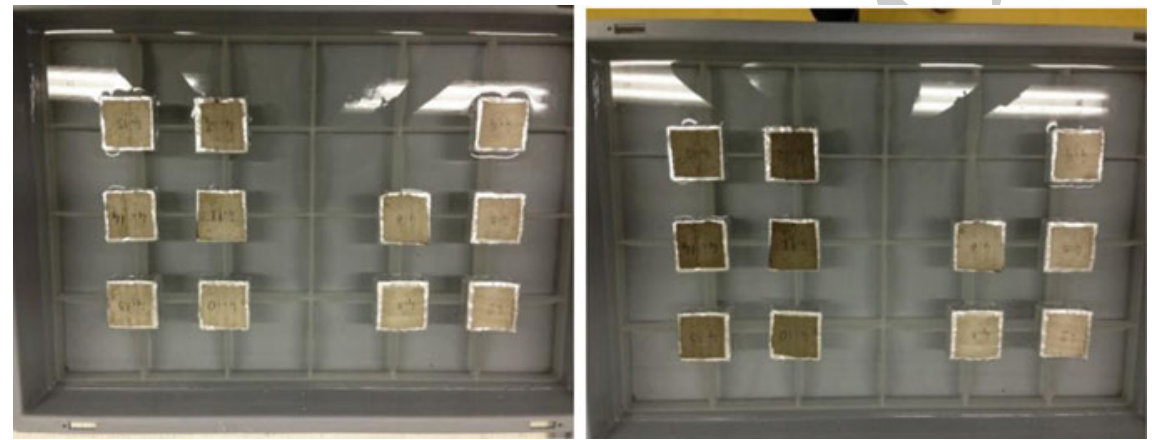

Fig. 8 CEM IV specimens after 5 min (left) and after $40 \min ($ right $)$; the samples on the right in each picture are treated, and those on the left are untreated
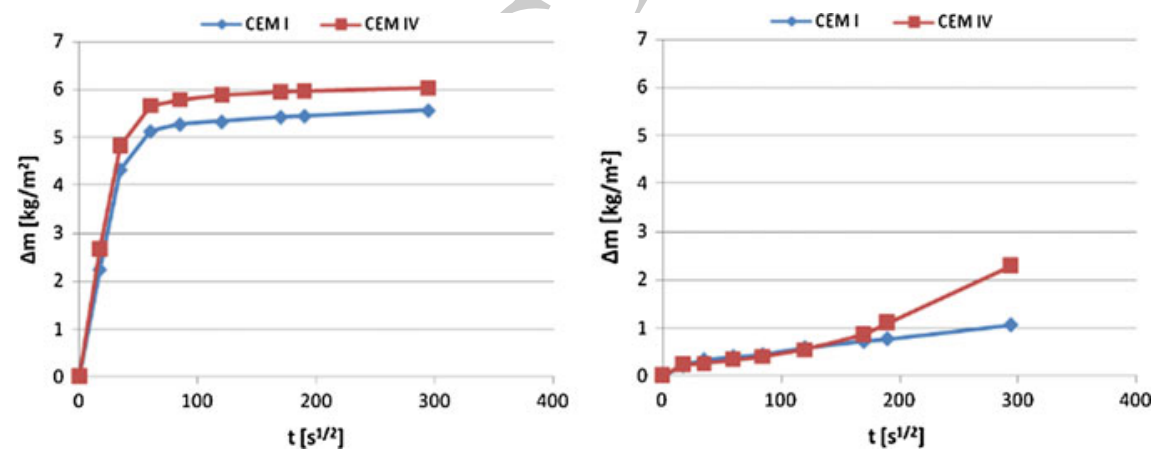

Fig. 9 Curves of water absorption by partial immersion for cement mortars (untreated specimens: left; treated specimens: right)

Table 2 Water absorption coefficient by partial immersion for the mortars specimens CEM I and CEM IV (untreated-treated)

\begin{tabular}{l|l|l|l}
\hline $\begin{array}{l}\text { Type } \\
\text { of mortar }\end{array}$ & $\begin{array}{l}\text { Aw }\left(\mathrm{kg} / \mathrm{m}^{2} \mathrm{~s}^{0.5}\right) \\
\text { before treatment }\end{array}$ & $\begin{array}{l}\text { Aw }\left(\mathrm{kg} / \mathrm{m}^{2} \mathrm{~s}^{0.5}\right) \\
\text { after treatment }\end{array}$ & $\begin{array}{l}\Delta \mathrm{Aw}\left(\mathrm{kg} / \mathrm{m}^{2} \mathrm{~s}^{0.5}\right) \\
\text { before-after treatment }\end{array}$ \\
\hline CEM I & 0.125 & 0.003 & 0.122 \\
\hline CEM IV & 0.139 & 0.005 & 0.134 \\
\hline
\end{tabular}


Table 3 Differences between the water absorption coefficients by capillarity/partial immersion for the mortars specimens (untreated-treated)

\begin{tabular}{l|l|l|l|l|l|l}
\hline $\begin{array}{l}\text { Type of } \\
\text { mortar }\end{array}$ & $\begin{array}{l}\mathrm{Aw} \\
\left(\mathrm{kg} / \mathrm{m}^{2} \mathrm{~s}^{0.5}\right) \\
\text { before } \\
\text { treatment }\end{array}$ & $\begin{array}{l}\mathrm{Aw} \\
\left(\mathrm{kg} / \mathrm{m}^{2} \mathrm{~s}^{0.5}\right) \\
\text { after } \\
\text { treatment }\end{array}$ & $\begin{array}{l}\mathrm{AC} \\
\left(\mathrm{kg} / \mathrm{m}^{2} \mathrm{~s}^{0.5}\right) \\
\text { before } \\
\text { treatment }\end{array}$ & $\begin{array}{l}\mathrm{AC} \\
\left(\mathrm{kg} / \mathrm{m}^{2} \mathrm{~s}^{0.5}\right) \\
\text { after } \\
\text { treatment }\end{array}$ & $\begin{array}{l}\Delta \mathrm{Aw}-\mathrm{AC} \\
\left(\mathrm{kg} / \mathrm{m}^{2} \mathrm{~s}^{0.5}\right) \\
\text { before } \\
\text { treatment }\end{array}$ & $\begin{array}{l}\Delta \mathrm{Aw}-\mathrm{AC} \\
\left(\mathrm{kg} / \mathrm{m}^{2} \mathrm{~s}^{0.5}\right. \\
\text { after } \\
\text { treatment }\end{array}$ \\
\hline CEM I & 0.125 & 0.003 & 0.065 & 0.002 & 0.060 & 0.001 \\
\hline CEM IV & 0.139 & 0.005 & 0.100 & 0.003 & 0.039 & 0.002 \\
\hline
\end{tabular}

$A w$ water absorption coefficient by partial immersion

$C A$ water absorption coefficient by capillarity

directly in contact with water in the test of absorption by partial immersion, while in the test by capillarity, there is a layer of interposed paper. The differences between the two coefficients are negligible when considering treated samples, while for untreated samples, in particular for CEM I, the difference is quite significant.

\subsection{Determination of Water Vapor Transmission Properties}

The researchers tested the specimens following the standard UNI EN 15803, 2010, after the desiccation at $60{ }^{\circ} \mathrm{C}$ until reaching constant mass, to avoid alterations, especially once applied the water-repellent treatment (Fig. 10).

Table 4 shows the results of the mean values of water vapor resistance factors for the different types of mortars before and after the application of the siloxane product.

It is possible to notice that the values with and without the water-repellent treatment are almost equal, and therefore, the application of the product SILO 111 on cement samples does not add resistance to the flow of vapor.
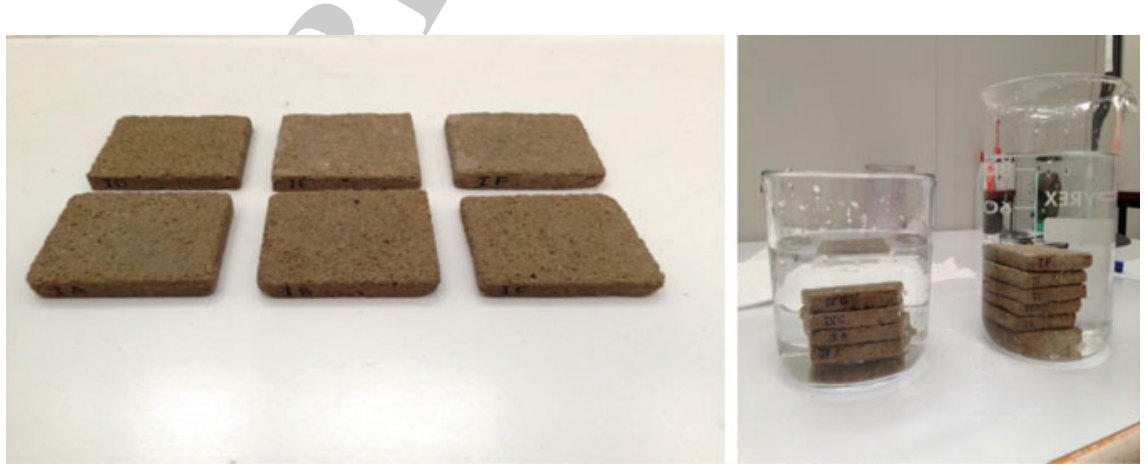

Fig. 10 Preparation of the sample for the evaluation of water vapor transmission properties: The images shows the cement samples placed in a container of deionized water 
Table 4 Water vapor resistance factor for untreated/treated samples

\begin{tabular}{l|l|l}
\hline $\begin{array}{l}\text { Type of } \\
\text { mortar }\end{array}$ & $\begin{array}{l}\mu[-] \text { before } \\
\text { treatment }\end{array}$ & $\begin{array}{l}\mu[-] \text { after } \\
\text { treatment }\end{array}$ \\
\hline CEM I & 13 & 14 \\
\hline CEM IV & 10 & 12 \\
\hline
\end{tabular}

\subsection{Determination of Long-Term Water Absorption by Immersion}

The determination of long-term water absorption by immersion has been performed following the standard UNI EN 12087, 2013.

The researchers studied the coefficient of long-term water absorption by immersion only for untreated cement samples. The long-term water absorption by total immersion is determined by measuring the change in mass of the test specimen, totally immersed in water, over a period of 28 days (Table 5).

Figure 11 shows the long-term water absorption by total immersion.

\subsection{Color Test}

The color measurement has the aim to evaluate the chromatic alterations caused by the application of the water-repellent treatment SILO 111 on the mortar specimens.

The researchers carried the measures out according to the standard UNI EN 15886, 2010. The method is based on the reflectance measures, which express the color as a number. Colors are represented in a solid or "color space" in which each point is univocally defined by three spatial coordinates to which correspond a defined color of the visible spectrum.

Table 5 Long-term water absorption value $W_{\mathrm{f}}$ by total immersion

\begin{tabular}{l|l}
\hline Specimen & $W_{\mathrm{f}}\left(\mathrm{kg} / \mathrm{m}^{3}\right)$ \\
\hline CEM I & 224.7 \\
\hline CEM IV & 260.7 \\
\hline
\end{tabular}

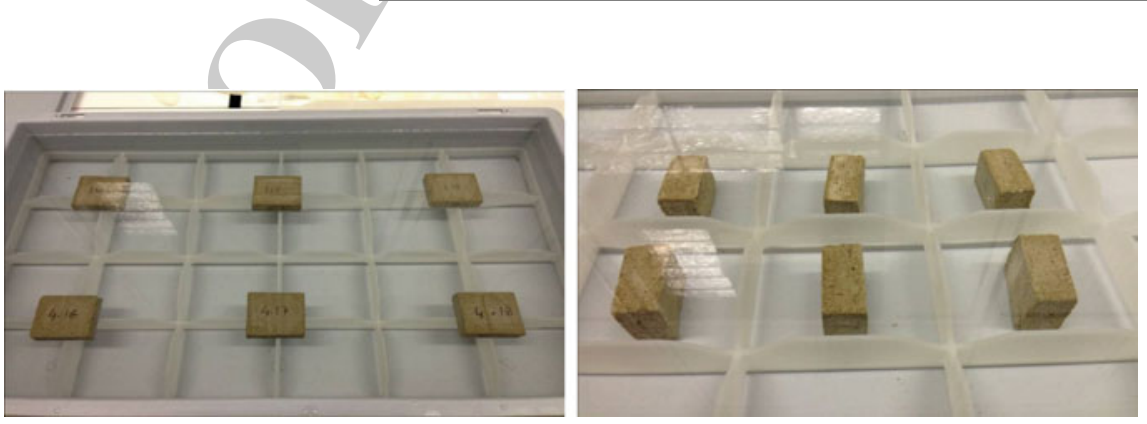

Fig. 11 Long-term water absorption performed on cement samples 

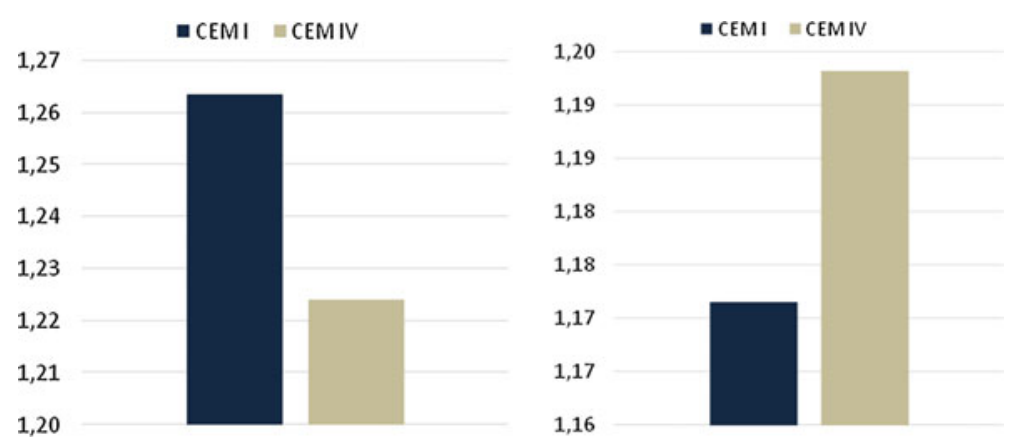

Fig. 12 Total color difference $\Delta \mathrm{E}$ (left) and total shade difference $\Delta \mathrm{H}$ (right) between the two cement types

In this test, the system of measurement of the color is the CIE $L^{*} a^{*} b^{*}$ (1976) according to the Commission Internationale de l'Eclairage (1931). The system is based on the mathematical transformation of the CIE space in a three-dimensional Euclidean space.

The variable $L^{*}$ represents the measure of the brightness in a range from 0 to $100 ; a^{*}$ and $b^{*}$ are the coordinates of the point of color in a Cartesian plane. Their values can be positive or negative, or can be equal to zero for both values for a neutral color (white, gray, black). The measurement was taken with a colorimeter Minolta $\mathrm{Cr}-200$. The test procedure involves 25 measures for each specimen. The values of $L^{*}, a^{*}$, and $b^{*}$ are the mean values of the 25 measures, taken to minimize the error due to the presence of chromatic irregularities on the surfaces of the specimens (Fig. 12).

The diagram shows that the application of the water-repellent treatment does not affect the surface color ( $\Delta \mathrm{E}$ ranging from 1.20 to 1.30 ). In fact, values around 1 are considered very good and not perceivable by naked eye.

\subsection{Solar Reflectance}

Spectrophotometry is the quantitative measurement of the reflection or transmission properties of a material as a function of the wavelength. The study aims to investigate the changes in reflection of mortars when the siloxane treatment is applied. The following graph of absorption versus wavelength (spectrum) presents the results on untreated and treated cement mortars specimens.

The solar reflectance tests follow the standard ASTM E903-12 (2012). The researchers selected 20 cement specimens CEM I and 20 cement specimens CEM IV: specimens $1.2-1.6$ and $4.2-4.6$ have a siloxane treatment, while from 1.10 to 1.21 and from 4.10 to 4.21 are untreated. For each specimen, two measures have been carried out. The spectral reflectance was measured with a Perkin-Elmer Lambda 900 Spectrophotometer. 
The machine was equipped with a 150-mm Spectralon-coated integrating sphere, a photomultiplier tube, and lead sulfide detectors. The authors measured the reflectance and compared the measurements to a Spectralon-calibrated reference in the 300-2500-nm wavelength range with a spectral resolution of $5 \mathrm{~nm}$ (Paolini et al. 2014). Two points of each sample lit by the measurement beam were used for the analysis; thus, the surface variations were considered. For each cement type of mortar (untreated-treated, CEM I-IV), the researchers computed the average spectral curve and then the integrated values.

Focusing on the spectral data, the portions of the solar spectrum where the treatment has the largest impact on the variations in reflectance can be determined (Fig. 13).

The main differences between CEM I and IV are visible at NIR; nevertheless, in general, the distance among the curves is constant along all the wavelengths. The trend of the measures of untreated and treated specimens is almost equal at NIR and becomes evidently different at VIS and UV, where it decreases for both the types of cement.

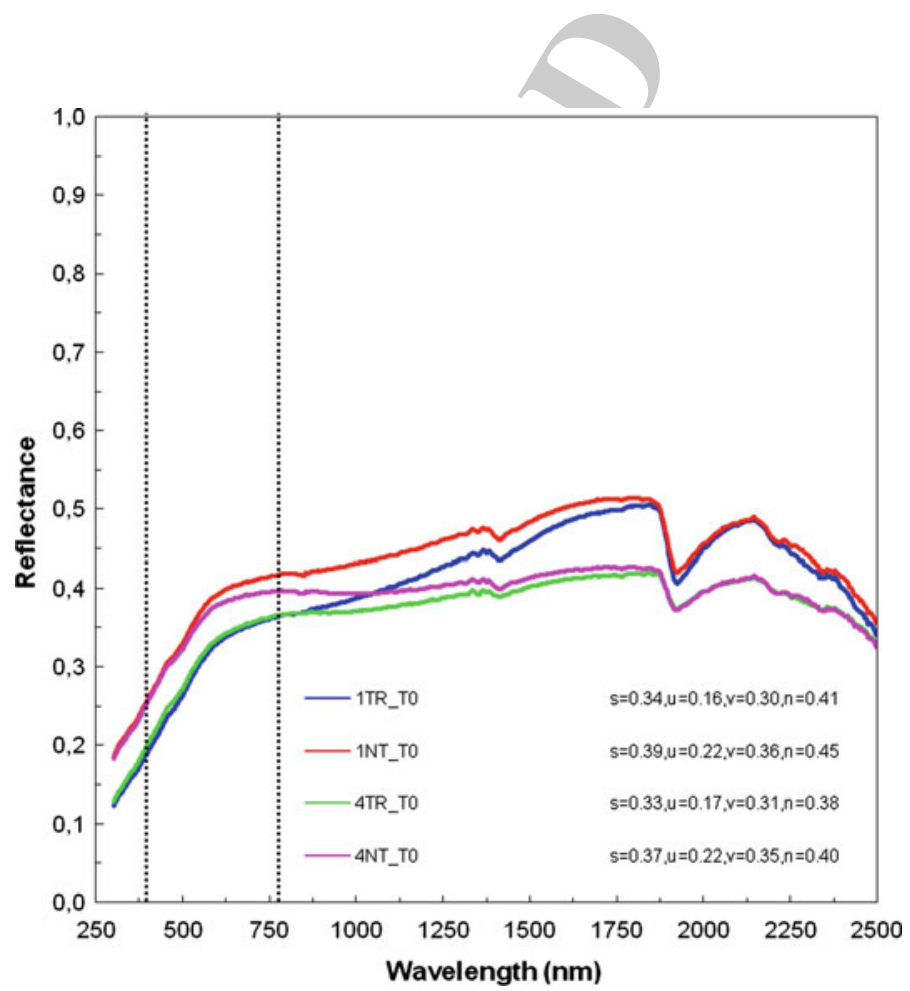

Fig. 13 Spectral and computed solar $(s)$, UV $(u)$, visible $(v)$, and near infrared $(n)$ reflectance performed before exposure; the curves of the specimens with siloxane treatment are TR, whereas the untreated are NT 


\section{Heat and Moisture Transfer}

The research has shown that the conservation of historic building facades is closely linked to the moisture control and to the water transfer inside the components. An adequate evaluation of these factors is unavoidable to produce accurate and timely interventions. However, the experiments in laboratory and on-site are time- and money-consuming, and the possibility to trust on computer-based simulations would be useful and would guarantee savings (Künzel 1995; Krus 1996).

For this reason, the last part of the research deals with the validation of the results through computer simulations and the development of a set of data for the investigated building materials, and in particular, cement mortars evaluated with a water-repellent protective treatment.

The researchers used the program WUFI (Wärme und Feuchte instationärTransient Heat and Moisture), developed by Fraunhofer Institute for Building Physics. It allows the use of data derived from outdoor and laboratory tests for the development of realistic simulations of the transient hygrothermal behavior of building materials and components, exposed to natural climate conditions.

The first step for the assessment of moisture transfer by numerical simulation has been the search through laboratory tests of the necessary material data set, which have been evaluated according to the standard UNI EN 15026 (2008). The thermo-hygrometric characterization of the mortars performed in laboratory and on site supported the simulations with the specific data of the materials of the analyzed case studies. However, during the simulations, the researchers used also the data of materials already existing in the database to catch the differences and understand the influence of the characterization data on the results. Moreover, they referred to the database for the characterization of the other materials composing the walls, which did not go under investigation in this research.

The specific boundary conditions have been referred to Milan and compared to the available data. The dynamic simulations are fundamental in case of the external layer evaluation, which is directly affected by the microclimatic variations occurring in the environment (Marra 2011).

Aim of the simulation was to support the choice of the best formulation in terms of compatibility and moisture absorption, simulating the behavior of the two mortars mix design with/without the application of the water-repellent treatment. For the sake of the research, the authors considered only the stratigraphy in correspondence with the mortar joints, and therefore, the model of the hygrothermal behavior of the components has been performed using WUFI-1D. A further development of the study implies 2D simulations especially in the case of tiles cladding systems, where the two sections of the finishing (mortar joints/tiles and embedded mortar) contribute in a different way to the final moisture balance of the façade.

The researchers investigated the northern façade of Building 12, Campus Leonardo, and in particular focused the simulations on the bedding mortar layer. In fact, the thermographic analysis performed on the elevation underlined the presence 
of adhesion problems distributed on the external cladding system. They assume a constant geometry of the mortar layer without swelling and shrinkages.

\subsection{Material Properties and Boundary Conditions}

According to the standard UNI EN 15026, 2008, Table 6 shows the list of the material properties, which are necessary for the simulations. The list of the hygrothermal properties are for both untreated and treated materials, according to the laboratory tests availability. The tests described in the previous paragraphs provided the measured values, which correspond to the following:

- bulk density $\rho\left(\mathrm{kg} / \mathrm{m}^{3}\right)$.

- moisture storage function (sorption curve) $w \varphi$, according to the UNI EN ISO 12571, 2001.

- diffusion resistance factor $\mu$. For the sake of the research, aimed at evaluating the permanence of the vapor permeability by the treatment, the researchers followed the standard UNI EN 15803, 2010. Actually, the values used for the simulations in WUFI are those obtained by dry-cup tests, according to the UNI EN ISO 12572, 2006. For these reasons, the measured values were verified with tabulated ones (ISO 10456 2007) and performed a sensitivity analysis. The values are comparable and do not affect the final results.

- liquid conductivity $K$ that has been determined by the approximations using the water absorption coefficient by partial immersion (UNI EN ISO 15148, 2003). Moreover, the differences between the coefficients by partial immersion and capillarity observed for cement mortars appear not significant, especially for treated samples. For this reason, the researchers decided to use the values obtained from water absorption by capillarity test.

Table 6 Material data set and properties used in the simulations

\begin{tabular}{l|l|l|l}
\hline & CEM I & CEM IV & \\
\hline$\rho\left(\mathrm{kg} / \mathrm{m}^{3}\right)$ & 1928 & 1867 & Measured \\
\hline$\varepsilon\left(\mathrm{m}^{3} / \mathrm{m}^{3}\right)$ & 0.3 & 0.3 & Tabulated \\
\hline$c_{\mathrm{p}}(\mathrm{J} / \mathrm{kg} \mathrm{K})$ & 850 & 850 & Tabulated \\
\hline$\lambda(\mathrm{W} / \mathrm{m} \mathrm{K})$ & 1.2 & 1.2 & Tabulated \\
\hline$\mu[-] \mathrm{NT}$ & 13 & 10 & Measured \\
\hline$\mu[-] \mathrm{TR}$ & 14 & 12 & Measured \\
\hline Aw $\left(\mathrm{kg} / \mathrm{m}^{2} \mathrm{~s}^{0.5}\right) \mathrm{NT}$ & 0.125 & 0.139 & Measured \\
\hline Aw $\left(\mathrm{kg} / \mathrm{m}^{2} \mathrm{~s}^{0.5}\right) \mathrm{TR}$ & 0.003 & 0.005 & Measured \\
\hline $\mathrm{AC}\left(\mathrm{kg} / \mathrm{m}^{2} \mathrm{~s}^{0.5}\right) \mathrm{NT}$ & 0.065 & 0.100 & Measured \\
\hline AC $\left(\mathrm{kg} / \mathrm{m}^{2} \mathrm{~s}^{0.5}\right) \mathrm{TR}$ & 0.002 & 0.003 & Measured \\
\hline$\alpha[-] \mathrm{NT}$ & 0.61 & 0.63 & Measured \\
\hline$\alpha[-] \mathrm{TR}$ & 0.66 & 0.67 & Measured \\
\hline $\mathrm{Th}$ & $\mathrm{Hnt}$ &
\end{tabular}

The untreated mortars are defined as NT, whereas the treated ones as TR 
- free water saturation $\left(\mathrm{kg} / \mathrm{m}^{3}\right)$ taken from the laboratory tests according to the standard UNI EN 12087, 2013.

- shortwave (solar) radiation absorptivity [-] available for untreated cement mortars, according to the standard ASTM E903-12, 2012.

The other parameters [porosity $\varepsilon\left(\mathrm{m}^{3} / \mathrm{m}^{3}\right)$, specific heat capacity of dry material $\operatorname{cp}(\mathrm{J} / \mathrm{kg} \mathrm{K})$, and thermal conductivity of dry material $\lambda(\mathrm{W} / \mathrm{mK})]$ have been defined considering the standard ISO 10456, 2007.

The boundary conditions are defined in relation to the simulation to be modeled. The first analysis has regarded the validation of the laboratory test about hygroscopic absorption, and therefore, the researchers set up the boundary conditions according to the specific temperature and relative humidity inside the climatic chamber.

The second set of simulations regarded the evaluation of the real behavior of the mortars, in order to verify the efficacy of the water-repellent treatment in terms of water absorption reduction.

\subsection{Simulation Modeling}

The first analysis performed with WUFI-1D has been modeling the hygrothermal behavior of the mortar specimens obtained in the laboratory, to verify the data resulted from experimental tests (Marra 2011).

This series of simulation has been developed considering a mortar layer $2 \mathrm{~cm}$ thick, which corresponds to the thickness of the mortars specimens used in the laboratory. In the case of treated surfaces, the mortar has been divided in two parts: In the first, the researchers inserted the values obtained on the treated specimens and in the second the untreated ones, since the researchers assumed that the protective treatment properties are to be considered in the first centimeter of product penetration. They have defined the boundary conditions considering constant temperature at $20^{\circ} \mathrm{C}$, while imposing different steps in the relative humidity, corresponding to those used in the climatic chamber during the hygrothermal absorption tests $(0$, $30,50,70$, and $90 \%$ ). The initial relative humidity of the component has been zero since the specimens remained in the desiccator until they reach the constant weight before the test.

The duration of the desiccation was two week ( $336 \mathrm{~h}$ ) for the first two RH steps $(30,50 \%)$ and of four weeks $(672 \mathrm{~h})$ for the remaining steps $(70,90 \%)$.

In the analysis, the conditions imposed on both the sides of the samples are equal since the specimens were freely in contact with the environment inside the climatic chamber. In this case, it should be noted that in WUFI, only two surfaces are considered at the moisture balance, while in the laboratory tests also the sides contributed to the hygroscopic exchanges. 
In the second set, the researchers simulated the presence of a plastic film, since during the laboratory tests a plastic waterproof paraffin film sealed the boundary of the specimens, leaving only one free surface exposed toward the environment. They considered 3 measurement points placed, respectively, on the surface $(0 \mathrm{~m})$ at $0.05 \mathrm{~m}$ in depth and in the center of the sample $(0.01 \mathrm{~m})$ to monitor the trend of relative humidity along the thickness of the layer.

Figure 14 shows the simulations for CEM I mortar; nevertheless, the results were similar also for CEM IV.

In general, it is possible to notice that the component reaches the equilibrium with the environment in a longer time when relative humidity is increasing.

Adding the waterproof layer, the time to reach equilibrium increases with respect to the simulations considering free specimens, since the area exposed is reduced. Treated specimens reach faster the equilibrium.

The second objective of the simulations was to verify the best mortar mix design in terms of the lowest moisture absorption among those investigated. In the following, the researchers have performed simulations on treated mortars to verify the effectiveness of the applied siloxane water-repellent treatment (SILO 111) (Fig. 15).

The graph shows a reduction of absorbed water and in the water content peaks in the specimens treated with the siloxane product SILO 111 with respect to the untreated mortar.

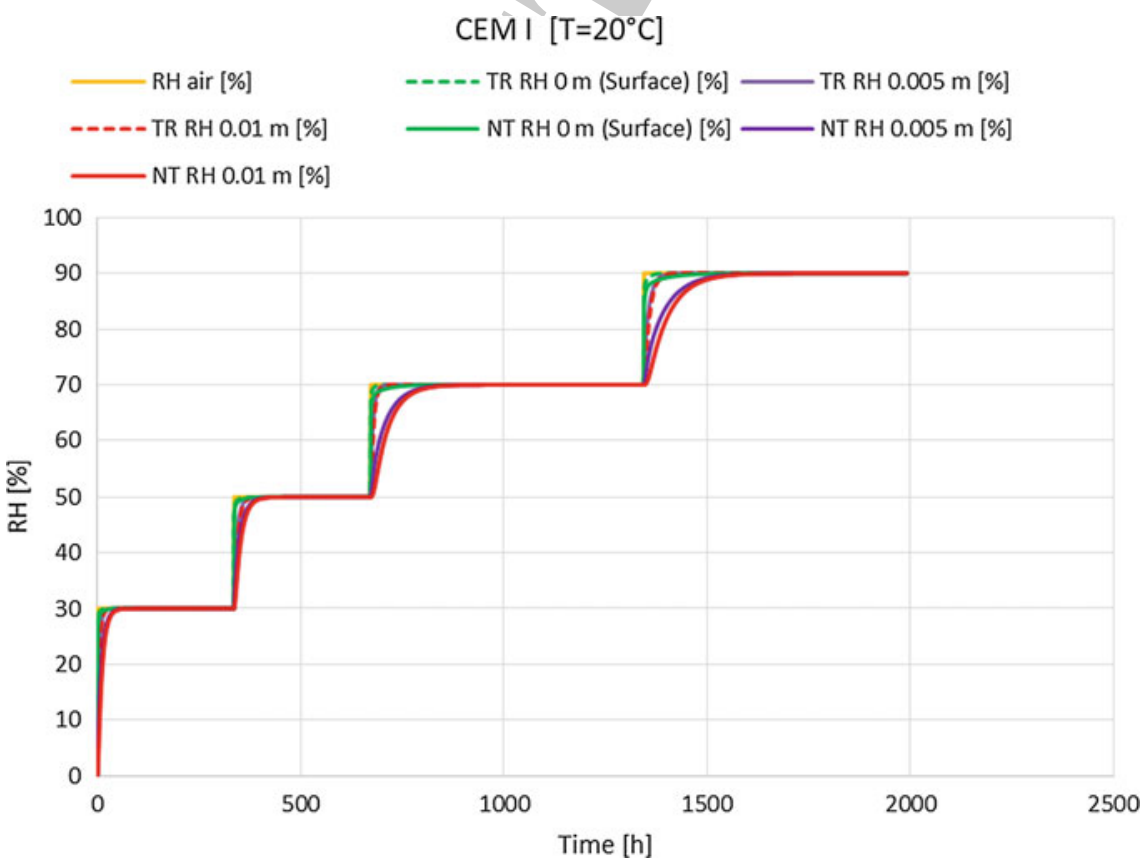

Fig. 14 Comparison of the RH trends for untreated/treated cement (CEM I) specimens 


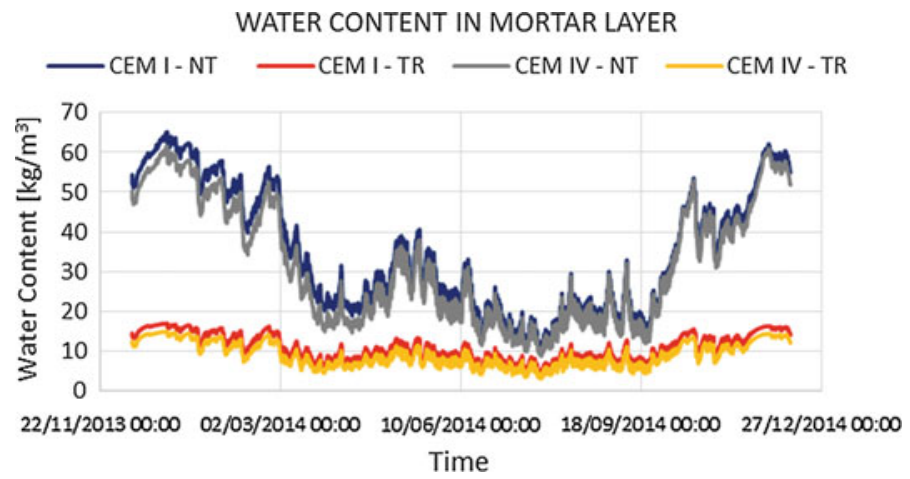

Fig. 15 Comparison of the water content trend in the external mortar (joints-section) for treated/untreated cements specimens

The trend for the two cement mortar types is equal even if CEM IV shows a higher reduction both in the treated and in the untreated curve.

Moreover, from the reported graphs, the dependency on the seasons of the trend of water content is apparent in the untreated specimens: in spring/summer, it is equal to $20 \mathrm{~kg} / \mathrm{m}^{3}$, while in autumn/winter, it is around $50 \mathrm{~kg} / \mathrm{m}^{3}$. Instead, for the treated specimens, it is almost constant. These simulations have shown the efficacy of the treatment in terms of absorbed water in the external mortar layer.

\section{Conclusions}

The presented work suggests a methodology for the evaluation of moisture transfer in bedding mortar layers to improve the conservation of clinker facades. Besides, the results of the monitoring and of the experiments provide effective indications for the correct strategies of maintenance (Daniotti et al. 2014a, b).

The investigations on the application of the water-repellent siloxane treatment SILO 111 show that the analyzed mortars fulfill the requirements necessary for the protection of humid walls (Künzel et al. 2004). Moreover, the treatment has shown its water-repellent effectiveness and its vapor permeability: the water vapor resistance factor, obtained through the experiments in laboratory, basically, remains constant between untreated/treated samples. Besides, it is resistant to thermo-hygrometric variations, it does not provoke chromatic alteration on the surfaces, and it is compatible with the substrate. The computer simulations on moisture transfer validated the results obtained through the laboratory tests and verified the effectiveness of the siloxane protective treatment in terms of reduction of absorbed water. 


\section{References}

Allen NS, Edge MD, Horie CV (1992) Polymers in conservation. Royal Society of Chemistry, Cambridge

Amoroso G, Camaiti M (1997) Scienza dei materiali e restauro. Alinea Editrice

Amoroso GG, Fassina V (1983) Stone decay and conservation. Materials Science Monograph, 11

ASTM E903-12 (2012) Standard test method for solar absorptance, reflectance, and transmittance of materials using integrating spheres

Caglio S, Redaelli V, Gargano M, Ludwig N, Rosina E (2011) The surfaces of contemporary architecture: carachterization of clinker by IRT. In: Proceedings of 11th international workshop on advanced infrared technology and applications. L'Aquila, pp 1-10

Coppola L (1996) Umidità nelle costruzioni: diagnosi e rimedi. In Presenza tecnica, pp 79-86)

Daniotti B (2009) Building durability and maintenance. Cusl, Milano

Daniotti B, Erba S, Rosina E (2014) Development of a methodological procedure for the durability evaluation of existing exterior finishings. In: Proceedings of XIII international conference on durability of building materials, Sao Paulo

Daniotti B, Erba S, Moioli R, Rosina E, Sansonetti A (2014) PPC at Lavello Convent: towards a sustainable conservation plan after the restoration. In: Proceedings of the PPC conference: preventive and planned conservation, Monza-Mantova

De Freitas SS, De Freitas VP, Barreira E (2014) Detection of façade plaster detachments using infrared thermography - a nondestructive technique. Constr Build Mater 70:80-87

Emídio FA (2012) Dissertação par a obtenção do Grau de Mestre em Engenharia Civil - Aplicação do método factorial à previsão da vida útil de revestimentos de pedra natural. Lisboa

Erba S (2015) Knowledge and diagnostics for the durability of external finishing systems. Doctoral dissertation in Building Engineering, Politecnico di Milano. Supervisor: Daniotti B, Co-Tutors: Rosina E, Sansonetti A

Horie CV (1987) Materials for conservation. Butterworth \& Co, London

ICOMOS International Scientific Committee (2008) ICOMOS-ISCS: Illustrated glossary on stone deterioration patterns. Champigny/Marne, France

Krus M (1996) Moisture Transport and storage coefficients of porous mineral building materials. Fraunhofer IRB Verlag

Künzel HM (1995) Simultaneous heat and moisture transport in building components. One- and two-dimensional calculation using simple parameters. Fraunhofer IRB Verlag

Künzel HM, Künzel N, Holm A (2004) Rain protection of stucco facades. In: Proceedings of the performances of envelopes of whole buildings IX conference. Clearwater Beach, Florida

Ludwig N, Rosina E, Caglio S, Gargano M, Redaelli V (2012) Heat diffusion in Klinker facade: the study case of a Giò Ponti building. Adv Opt Technol

Maldague X (ed) (2001) Non destructive testing handbook, 3rd edn, vol 3: Infrared and thermal testing. ASNT Columbus $(\mathrm{OH})$, USA

Maravelaki-Kalaitzaki P (2007) Hydraulic lime mortars with siloxane for waterproofing historic masonry. Cem Concr Res 283-290

Marra E (2011) Influenza dell'ambiente sulla corrosione degli inserti di acciaio nelle murature antiche. Doctoral dissertation in building engineering, Politecnico di Milano. Tutors: Daniotti B, Bertolini L

Mavrov G (1983) Aging of silicone resins. Stud Conserv 28:171-178

Nicolella M (2003) Programmazione degli interventi in edilizia. Guida al libretto di manutenzione del fabbricato. Maggioli Editore

Paolini R, Zinzi M, Poli T, Carnielo E, Mainini AG (2014) Effect of ageing on solar spectral reflectance of roofing membranes: natural exposure in Roma and Milano and the impact on the energy needs of commercial buildings. Energy Build 333-343

Re Cecconi F (1996) Metodologie e strumentazioni per la previsione della durabilità di componenti edilizi per edifici scolastici ai fini della loro programmazione manutentiva. Doctoral dissertation 
Sousa R (2008) Dissertação de Mestrado Integrado em Engenharia Civil - Previsão da vida útil dos revestimentos cerâmicos aderentes em fachada. Lisboa

Toniolo L, Poli T, Castelvetro V, Manariti A, Chiantore O, Lazzari M (2002) Tailoring new fluorinated acrylic copolymers as protective coatings for marble. J Cult Heritage 309-316

Tsakalof A, Manoudis P, Karapanagiotis I, Chryssoulakis I, Panayiotou C (2007) Assessment of synthetic polymeric coatings for the protection and preservation of stone monuments. $\mathrm{J}$ Cult Heritage 69-72

UNI EN 12087 (2013) Thermal insulating products for building applications. Determination of long term water absorption by immersion

UNI EN 15026 (2008) Hygrothermal performance of building components and building elements. Assessment of moisture transfer by numerical simulation

UNI EN 15801 (2010) Conservation of cultural property. Test methods. Determination of water absorption by capillarity

UNI EN 15803 (2010) Conservazione dei beni culturali - Metodi di prova - Determinazione della permeabilità al vapore d'acqua

UNI EN 15886 (2010) Conservazione dei Beni Culturali - Metodi di prova - Misura del colore delle superfici

UNI EN ISO 12571 (2001) Hygrothermal performance of building materials and products: determination of hygroscopic properties

UNI EN ISO 12572 (2006) Hygrothermal performance of building materials and products. Determination of water vapour transmission properties

UNI EN ISO 15148 (2003) Hygrothermal performance of building materials and products: Determination of water absorption coefficient by partial immersion

Velosa A, Veiga R, Martins G (2011) Water behaviour of old and new tiles-a contribution towards the conservation of ceramic facades. In: Proceedings of XII DBCM, Porto, Portugal 